\title{
Can NCI cut deaths in half?
}

\section{Washington}

CuTTING cancer deaths in half by the year 2000 is an achievable goal, according to the National Cancer Institute (NCI).In a monograph released last week* ${ }^{*} \mathrm{NCI}$ lays out its strategy for achieving that goal. But its critics worry that the plans may do more to maintain the health of NCI than they will to reduce cancer mortality.

Edward Sondik, coeditor of the monograph, says the NCI approach has two primary focuses; reducing smoking and improving treatment. In 1985, 462,000 people in the United States died of cancer, and NCI reckons 30 per cent of those deaths are attributable to tobacco. By 2000 , NCI hopes to reduce cancer mortality attributable to smoking by between 8 and 16 per cent, implying that the number of people who smoke must be reduced to a half within this decade. Although the percentage of the US population that smokes has been declining since 1965 , the rate of decline would have to double for males and considerably more than double for females for this goal to be achieved.

Reduction in mortality through treatment accounts for half the targeted decline. Using new communication tools such as the Physician Data Query (PDQ), a computerized information service, $\mathrm{NCI}$ hopes modern therapies will be more widely disseminated. $\mathrm{NCI}$ is also relying on regional cancer treatment centres and cooperating groups of physicians to test and implement new therapeutic regimens. But Sondik concedes that more than half of the projected improvements attributable to treatment must come from treatments yet to be proved effective.

In addition to smoking and therapy, the NCI report calls for changes in diet as well as more screening programmes for early detection. Reducing fat to 30 per cent of

\section{French research}

\section{Teetering on the brink}

Young French scientists who were offered jobs for life earlier this year by the leading French research council, the Centre National de la Recherche Scientifique (CNRS), but have since been denied this privilege, are taking their case to law.

The 522 people concerned were appointed by the usual procedures in the annual recruitment to the research council, but then were effectively dismissed by a government decree invalidating the appointing committees. The group accordingly formed a pressure group, the "Collectif des Admissibles", and appointed a lawyer to argue its case. Legal proceedings have now begun, in the highest court of the land, the Conseil d'État, against science minister Alain Devaquet, who issued the decree, and (in a lower court) against the director-general of the research council, Serge Feneuille.

Members of the group are also seeking substantial damages in private actions for loss of livelihood, expenses in relocation and other inconveniences. Meanwhile, the research council has offered one-year contracts to 285 of the 522 .

The background is complex and political. The Conseil d'État ruled on 12 May that certain elections to the appointments committees of the research council had been irregular. In the event, the necessary corrections could have been made when the committees were re-elected for 1987. But the arrival of the new government and, it is said, pressure from right-wing physicians discontented with the survival of CNRS is thought to have persuaded the government to take the ruling seriously.
Devaquet's decision to dissolve the CNRS appointments committees and to annul all appointments made this year seems not to have been strictly necessary in the wake of the Conseil d'État's ruling. That is the interpretation that many French scientists are putting on the affair.

But what effect will it have on French science? A new Comité National (the body of appointments committees) is to be elected next year. Feneuille, who comes from industry, is said to want to make the stopgap short-term contracts a permanent feature of CNRS life.

Next year's Comité National will have to consider which of the 285 short-term appointees from the original 522 'admissibles' should stay; there is no guarantee that all will. Those thinking of joining the research council are also in a quandary: will the 285 have priority, affecting the numbers of new staff to be appointed?

For the longer term, French researchers are having to come to terms with lower recruitment rates than previously expected, as well as lower budgets. They will also be facing a new Comité National, which, under a new constitution, will include representatives from the whole of the university teaching community, and not just from researchers as at present. In the harder sciences, where about 60 per cent of university staff are in research and in some way connected with the research council, the effects of this change may not be too great. But in medicine, where only 30 per cent do research, the new powers in control at CNRS may be evident.

Robert Walgate total calorie intake and increasing fibre to 20-30 grams per day will yield an estimated 8 per cent reduction in mortality by 2000 , according to the NCI report. Another 3 per cent reduction in mortality may be expected from wider use of Pap smears for all women over 20 and mammograms for women over 50 .

But critics feel the NCI figures are overly optimistic. John Cairns of the Harvard School of Public Health says NCI cannot justify the expected decreased mortality projected by the report. With cancer deaths currently around 450,000 annually, Cairns says NCI projections require that more than 100,000 deaths be prevented annually through treatment. Apart from breast cancer, where improved mortality rates have been achieved, saving approximately 10,000 lives annually, Cairns wonders where the other 90,000 or more will come from.

A debate is currently raging over whether NCI is winning the war on cancer (see the News and Views article by Jared Diamond in Nature 323, 488; 1986) which was officially declared in 1971, Sondik says improved long-term survival rates show that there have been significant strides in treatment for many types of cancer. But others argue that age-adjusted mortality statistics paint a less encouraging picture and that a dramatic turnaround will be needed to achieve NCI goals.

At the heart of the debate is whether $\mathrm{NCI}$ is receiving too large a share of the federal research budget, and whether that share is being spent properly. Critics say it has put too great an emphasis on treatment at the expense of prevention, but Sondik counters that prevention efforts currently account for about 28 per cent of NCI outlays. Treatment programmes have been receiving approximately 30 per cent of the NCI budget.

What cannot be gainsaid is that the NCI budget is large, and growing. In $1987 \mathrm{NCI}$ will receive approximately $\$ 1,400$ million, slightly less that one quarter of the total budget for the National Institutes of Health. NCI is seeking $\$ 1,700$ million for 1988. But its associate director Peter Fischinger is not sure the fight against cancer will cost much more in the future. $\mathrm{He}$ hopes that the mix of prevention, screening and treatment will achieve the desired results.

NCI's goal of halving cancer mortality by 2000 is not new, having been first announced in April 1984 at a congressional hearing. NCI has steadfastly maintained that dramatic reductions in cancer deaths are possible. But officials now sound a note of caution. Fischinger says the goals for 2000 are not testaments, only estimates. It will be up to Congress to decide whether those estimates are worth the hefty price tag.

Joseph Palca

* Cancer Control Objectives for the Nation: 1985 - $2000 \mathrm{NCI}$ Monograph No. 2; 1986. 